\title{
Brain-derived neurotrophic factor (BDNF) prevents the development of dia- betes in prediabetic mice
}

\author{
Mitsugu Yamanaka ${ }^{1}$, Yasushi Itakura ${ }^{2}$, Atsushi Tsuchida ${ }^{1}$, Tsutomu Nakagawa ${ }^{1}$ and Mutsuo Taijl ${ }^{1}$ \\ ${ }^{1}$ Discovery Pharmacology I, Pharmacology Research Laboratories, Dainippon Sumitomo Pharma Co., Ltd., 3-1-98 Kasugade Naka, Ko- \\ nohana-ku, Osaka 554-0022, Japan; and ${ }^{2}$ Product Strategy Group, Marketing Management, Dainippon Sumitomo Pharma Co., Ltd., \\ 1-12-2 Kyobashi, Chuo-ku, Tokyo 104-8356, Japan
}

(Received 24 March 2008; and accepted 15 April 2008)

\begin{abstract}
We previously reported that peripheral injection of brain-derived neurotrophic factor (BDNF) exhibits hypophagic and hypoglycemic effects in obese hyperglycemic animals, indicating its antiobesity and antidiabetic effects. Since previous studies were focused on the effect of BDNF on overt diabetic animals with severe hyperglycemia, there was no evidence whether BDNF is effective or not for the development of diabetes in prediabetic animal models. Therefore, we evaluated the effect of BDNF on preventing the development of diabetes in $d b / d b$ mice. First, we characterized age-related changes in the pathophysiology of diabetes in $d b / d b$ mice. We chose 8 week-old $d b / d b$ mice as the early diabetic stage (early intervention study) and 4 week-old $d b / d b$ mice as the prediabetic stage (prevention study). Next, we examined the effects of BDNF on the progression of diabetes in early diabetic $d b / d b$ mice. In the early intervention study using 8 week-old $d b / d b$ mice, intermittent treatment with BDNF prevented the deterioration in hyperglycemia. Lastly, we examined the preventive effects of BDNF on the development of diabetes in prediabetic $d b / d b$ mice. In the prevention study using 4 week-old $d b / d b$ mice, treatment with BDNF prevented the age-related increase in blood glucose concentration. These results showed for the first time that BDNF prevents the development of diabetes in prediabetic $d b / d b$ mice.
\end{abstract}

Type 2 diabetes is progressive disorder initially characterized by impaired glucose tolerance (IGT) and compensatory hyperinsulinemia and, in the later stages, by severe insulin resistance and impaired $\beta$-cell function (7). The syndrome is associated with hyperglycemia, dyslipidemia, hypertension, and obesity and, in the long term, micro- and macrovascular complications, resulting in impaired life quality and increased mortality $(5-7,10)$. IGT was first introduced 1979 by the National Diabetes Data Group (16) and the World Health Organization (WHO) Expert Committee on Diabetes (23) as an intermediate cat-

Address correspondence to: Dr. Mutsuo Taiji, Discovery Pharmacology I, Pharmacology Research Laboratories, Dainippon Sumitomo Pharma Co., Ltd., 3-1-98 Kasugade Naka, Konohana-ku, Osaka 554-0022, Japan Tel: +81-6-6466-5264, Fax: +81-6-6466-5182

E-mail: mutsuo-taiji@ds-pharma.co.jp egory covering the gray area between unequivocal diabetes mellitus and normal glucose tolerance. Early stage of diabetes also carries an increased risk of development of cardiovascular disease and forms part of the "metabolic syndrome" (9). Therefore, it is very important to treat early stage of diabetes as well as hyperglycemia in overt diabetes.

Brain-derived neurotrophic factor (BDNF) is a member of the neurotrophin family, which includes nerve growth factor, neurotrophin-3 and neurotrophin-4/5 $(1,13,14,19)$. BDNF promotes neurite outgrowth, provides trophic support to certain neurons in the central and peripheral nervous systems, and is efficacious in the treatment of neurological disorders $(18,26)$.

In addition to the efficacy of BDNF in neurological disorders, we and others reported that peripheral injection of BDNF exhibits hypophagic and hypoglycemic effects in obese hyperglycemic animals but 
not in normal animals, indicating its antiobesity and antidiabetic effects $(15,17,21)$. The efficacy of BDNF in ameliorating glucose metabolism was observed not only in the case of the repetitive administration but also in the case of the intermittent administration (25). Moreover, we have previously shown that concomitant administration of BDNF with insulin enhances the hypoglycemic action of insulin in streptozotocin (STZ)-induced type 1 diabetic mice (22) and BDNF administration protected against pancreatic exhaustion in obese diabetic mice (24). Since previous studies were focused on the effect of BDNF on diabetic animals with severe obese and hyperglycemia, there was no evidence whether BDNF is effective or not for the development of diabetes in prediabetic animal models.

In the current study, we characterized age-related changes in the pathophysiology of diabetes in $d b / d b$ mice. Next, to evaluate the preventive effect of BDNF on the development of diabetes, we examined the effect of BDNF on glycemic control in early diabetic or prediabetic $d b / d b$ mice. We presented here for the first time that BDNF prevented the development of diabetes of $d b / d b$ mice.

\section{MATERIAL AND METHODS}

Animals. Male C57BL/KsJ- $d b / d b$ mice were obtained from Clea Japan Inc. (Tokyo, Japan). Animals were housed under a temperature-, humidity-, and light-controlled room with a daily cycle of $12 \mathrm{~h}$ light and $12 \mathrm{~h}$ darkness. They were given free access to water and diet (CE-2; Clea Japan). All animal experiments were conducted in accordance with the guidelines of the Dainippon Sumitomo Pharma Committee on Animal Research.

BDNF administration. Human recombinant BDNF (N-terminal methionine-free; Regeneron Pharmaceuticals, Tarrytown, NY, USA) was administered twice a week subcutaneously to 4 or 8 week-old $d b / d b$ mice at $20 \mathrm{mg} / \mathrm{kg}$. A solution containing $0.01 \%$ Tween 80 and 1\% Mannitol in PBS (phosphate-buffered saline; $10 \mathrm{mM}$ phosphate and $150 \mathrm{mM} \mathrm{NaCl}$, $\mathrm{pH}$ 7.0) was used as the vehicle.

Measurement of blood glucose concentration, pancreatic and plasma insulin concentrations. Blood was sampled from the tail vein, and blood glucose concentrations were measured by the Antsense II blood glucose analyzer (Bayer Medical, Tokyo, Japan). Pancreas tissues were weighed, homogenized and extracted with acid ethanol solution (conc. $\mathrm{HCl}$ : ethanol:distilled $\left.\mathrm{H}_{2} \mathrm{O}=1.5: 75: 23.5\right)$ and the insulin concentration in the supernatant was measured. The pancreatic and plasma insulin concentrations were determined by Enzyme-Linked ImmunoSorbent Assay (ELISA) (Levis-insulin-mouse; Shibayagi, Gunma, Japan).

Oral glucose tolerance test (OGTT). After 8 weeks of treatment, oral glucose tolerance test was conducted as follows. After overnight fasting, $3 \mathrm{~g} / \mathrm{kg}$ D-glucose was administered orally to overnight-fasted $d b / d b$ mice. Blood glucose concentrations were measured at 0 (before), 45, 90, and $135 \mathrm{~min}$ after glucose administration.

Statistical analysis. All the data are presented as mean \pm SD. Differences between individual groups were analyzed by Student's $t$-test. The statistical calculations were performed using SAS software (SAS Institute, Cary, NC, USA), and $P<0.05$ was considered statistically significant.

\section{RESULTS}

The development of diabetes in $\mathrm{db} / \mathrm{db}$ mice

To investigate the protective effect of BDNF against the development of diabetes, first we characterized age-related changes in the pathophysiology of diabetes in $d b / d b$ mice. We measured the body weight, blood glucose concentration, plasma and pancreatic insulin concentrations of $d b / d b$ mice and non-diabetic control $\mathrm{db} / \mathrm{m}$ mice in the period of 11 weeks from 5 to 16 weeks old. As shown Fig. 1A, the initial (5 weeks old) body weight in $d b / d b$ mice was already significantly higher than that in $\mathrm{db} / \mathrm{m}$ mice $(28.5 \pm 1.0$ vs. $22.1 \pm 1.0 \mathrm{~g})$. The increment in body weight of $d b / d b$ mice during the experimental period was greater than that of $d b / m$ mice. As a consequence, 16 week-old $d b / d b$ mice exhibited severe obesity compared with age-matched $\mathrm{db} / \mathrm{m}$ mice ( 48.7 \pm 2.8 vs. $29.4 \pm 1.9 \mathrm{~g}$ ) (Fig. $1 \mathrm{~A}$ ). The initial (5 weeks old) blood glucose concentration in $d b / d b$ mice was slightly high compared with that in $\mathrm{db} / \mathrm{m}$ mice $(193 \pm 31$ vs. $147 \pm 12 \mathrm{mg} / \mathrm{dL}) . d b / d b$ mice showed a rapid increase in blood glucose concentration until 10 weeks old, whereas $\mathrm{db} / \mathrm{m}$ mice maintained normoglycemia $(428 \pm 33$ vs. $157 \pm 13 \mathrm{mg} / \mathrm{dL})$ (Fig. 1B). After 10 weeks old, $d b / d b$ mice exhibited severe hyperglycemia and kept it for the experimental period (Fig. 1B).

Plasma insulin concentration of 5 week-old $d b / d b$ mice was already extremely high compared with that in $\mathrm{db} / \mathrm{m}$ mice $(53.59 \pm 17.58$ vs. $1.29 \pm 0.74 \mathrm{ng} /$ 

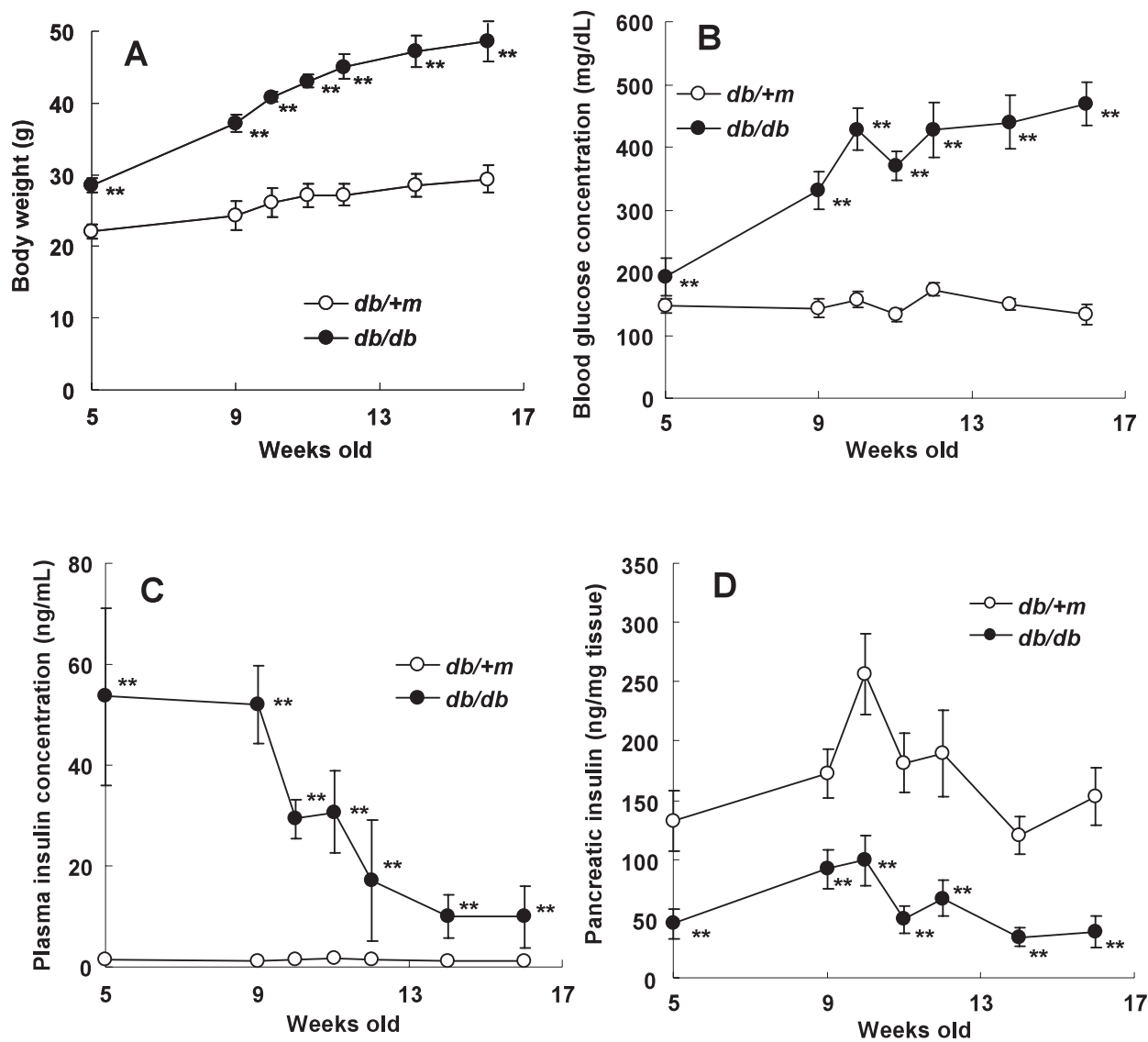

Fig. 1 Body weight (A), blood glucose concentration (B), and plasma (C) and pancreatic (D) insulin concentrations of $d b /$ $d b$ mice and $d b / m$ mice. Data are expressed as mean \pm SD $(n=8) .{ }^{* \star} P<0.01 \mathrm{vs} . d b / m$ mice by Student's $t$-test.

$\mathrm{mL}$ ) (Fig. 1C). The plasma insulin concentration in $d b / d b$ mice was kept at high level until 9 weeks old, and then decreased rapidly (Fig. 1C). The initial (5 weeks old) pancreatic insulin content in $d b / d b$ mice was significantly lower than that in $\mathrm{db} / \mathrm{m}$ mice $(45.7$ \pm 12.8 vs. $132.6 \pm 25.4 \mathrm{ng} / \mathrm{mg}$ tissue) (Fig. 1D). Pancreatic insulin content in $d b / d b$ mice increased gradually until 10 week-old, and then decreased (Fig. 1D). Therefore, in this study, we chose 8 week-old $d b / d b$ mice as the early diabetic stage (early intervention study) and 4 week-old $d b / d b$ mice as the prediabetic stage (prevention study).

Effect of twice-a-week administration of BDNF on glycemic control in early diabetic $d b / d b$ mice (early intervention study)

We have previously showed that the intermittent administration of BDNF ameliorates glucose metabolism in overt diabetic mice (25). In the previous study, BDNF was administered twice a week to overt diabetic 10 week-old $d b / d b$ mice. In the BDNF-treated mice, the blood glucose concentration dose-dependently decreased, with a significant effect at $10 \mathrm{mg} / \mathrm{kg}$ or more administered compared with that in the vehicle-treated $d b / d b$ mice (25). Based on this result, we examined the efficacy of BDNF administered twice a week to early diabetic 8 weekold $d b / d b$ mice at $20 \mathrm{mg} / \mathrm{kg}$ for 8 weeks. As shown Fig. 2A, an age-related increase in blood glucose concentration was observed in the vehicle-treated $d b / d b$ mice. In contrast, BDNF-treated $d b / d b$ mice maintained the initial blood glucose concentration during the treatment period, showing the prevention against the progression of diabetes. Body weight and food intake of the BDNF-treated $d b / d b$ mice also tended to be lower than those of the vehicletreated $d b / d b$ mice (Figs. 2B and 2C). We also performed OGTT after 8 weeks administration of BDNF. After overnight fasting, blood glucose concentrations in the BDNF-treated $d b / d b$ mice were significantly lower than those in the vehicle-treated $d b / d b$ mice (206 \pm 96 vs. $320 \pm 49 \mathrm{mg} / \mathrm{dL}$ ) (Fig. 3A). The area under the curve (AUC) of blood glucose concentration of the BDNF-treated $d b / d b$ mice was 

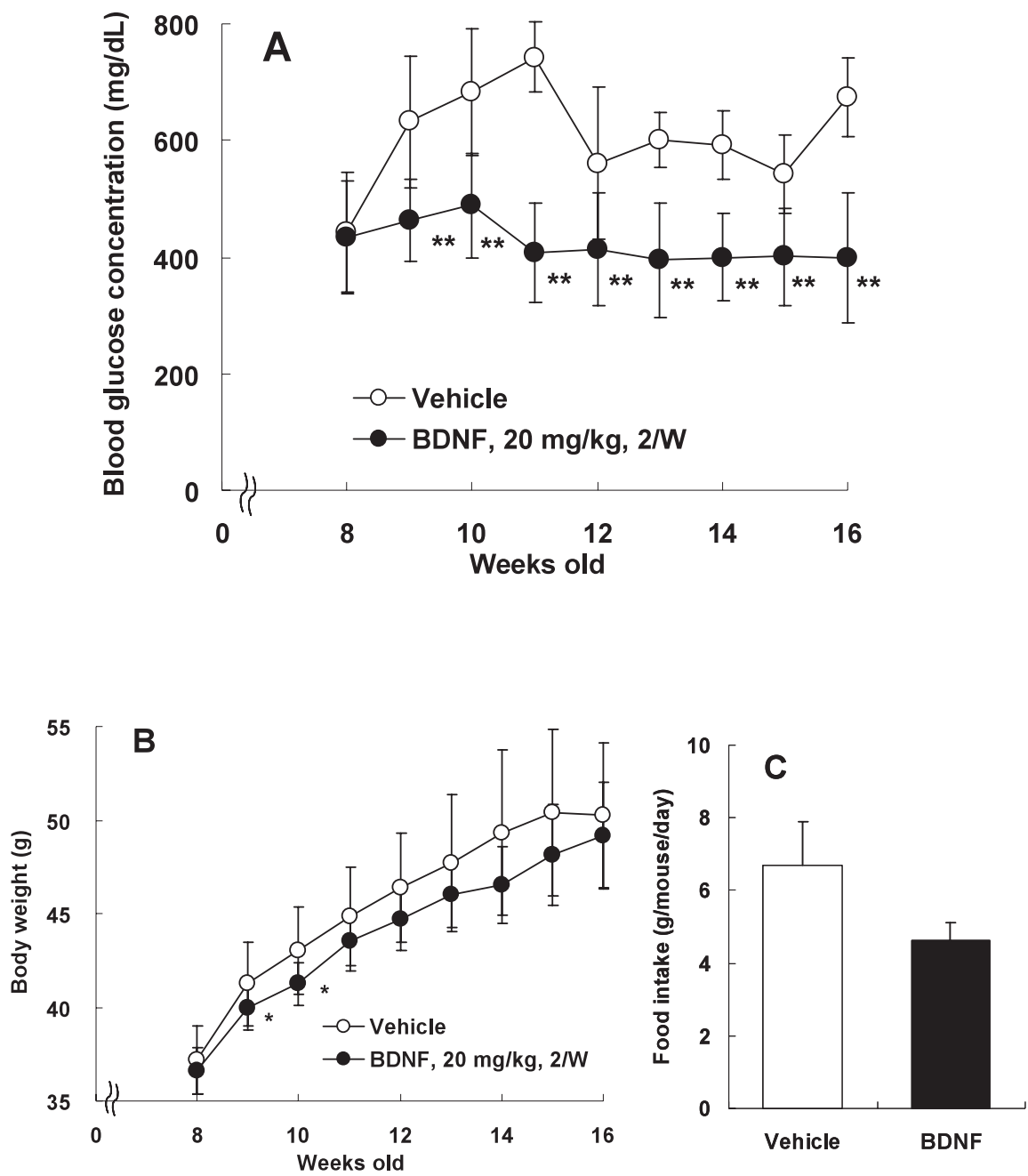

Fig. 2 Effect of intermittent administration of BDNF on early diabetic $d b / d b$ mice. BDNF (20 mg/kg) was administered twice-a-week to 8 week-old $d b / d b$ mice for 8 weeks. Blood glucose concentrations (A), body weight (B), and average of food intake during experimental periods $(C)$ were indicated. Data are expressed as mean \pm SD (vehicle; $n=7, B D N F ; n=8$ ). ${ }^{\star} P<0.05$ and ${ }^{\star \star} P<0.01$ vs. vehicle by Student's $t$-test.

significantly lower than the vehicle-treated $d b / d b$ mice during OGTT $(53519 \pm 54$ vs. $80916 \pm 81 \mathrm{mg}$ $\times \mathrm{min} / \mathrm{dL})$ (Fig. 3B).

Effect of twice-a-week administration of BDNF on glycemic control in prediabetic $d b / d b$ mice (prevention study)

Since twice-a-week administration of BDNF prevented the progression of diabetes in early diabetic $d b / d b$ mice, next we examined the preventive effect of BDNF on the development of diabetes in prediabetic $d b / d b$ mice. BDNF was administered twice a week to prediabetic 4 week-old $d b / d b$ mice at $20 \mathrm{mg} / \mathrm{kg}$ for 12 weeks. We measured the blood glucose concentration and body weight in these mice from 4 to 16 weeks old. In this study, blood glucose concentrations in the vehicle-treated $d b / d b$ mice increased from 5 to 11 weeks old, and were kept at high level (Fig. 4A). Interestingly, BDNF treatment mostly prevented the age-related increase in blood glucose concentration during the experimental period (Fig. 4A). Moreover, body weight of the BDNFtreated $d b / d b$ mice was lower than that of the vehicle-treated $d b / d b$ mice during the experimental period (Fig. 4B). These results demonstrated that intermittent administration of BDNF prevents the development of diabetes in prediabetic $d b / d b$ mice.

\section{DISCUSSION}

In this study, we characterized age-related changes in the pathophysiology of diabetes in $d b / d b$ mice. 

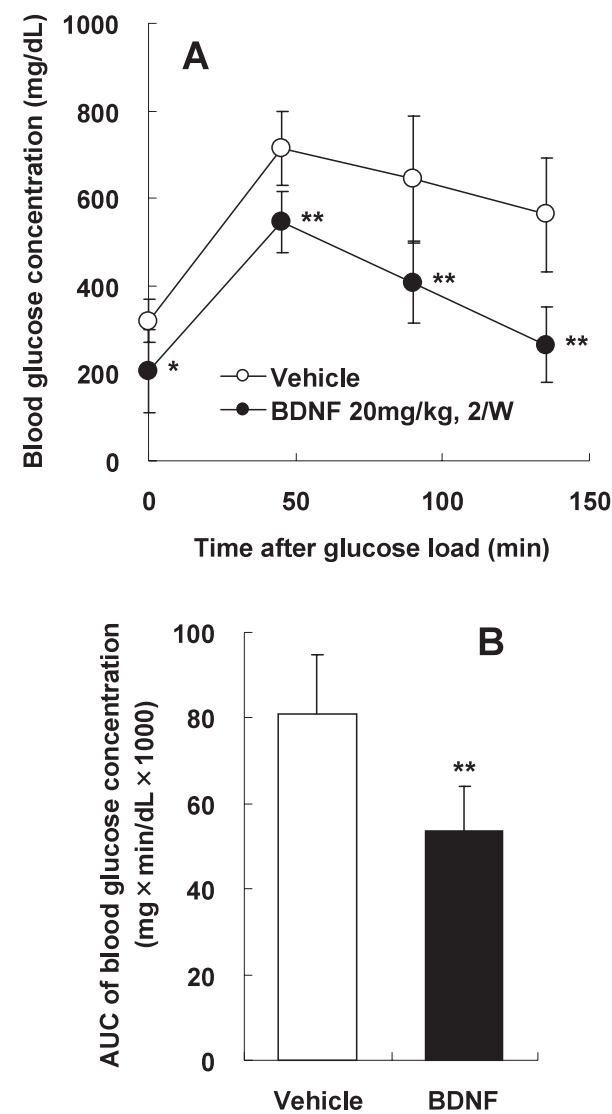

Fig. 3 Effect of intermittent administration of BDNF on glucose metabolism on early diabetic $d b / d b$ mice. OGTT was performed after 8 weeks administration of BDNF $(20 \mathrm{mg} /$ $\mathrm{kg})$. After the last administration, the mice were fasted overnight and $3 \mathrm{~g} / \mathrm{kg}$ of glucose was administered orally. Blood glucose concentrations at each time $(A)$ were measured and area under the curve (AUC) of blood glucose concentration (B) was calculated. Data are expressed as mean \pm SD (vehicle; $\mathrm{n}=7$, BDNF; $\mathrm{n}=8$ ). ${ }^{\star} P<0.05$, ${ }^{* *} P<0.01$ vs. vehicle by Student's $t$-test.

The age-related progression in diabetes of $d b / d b$ mice were summarized by showing plasma insulin and blood glucose concentrations (Fig. 5). In the relatively young $d b / d b$ mice from 5 to 9 weeks old, hyperinsulinemia and the gradual increase in blood glucose concentration were observed. Therefore, we supposed that $d b / d b$ mice in this period are early diabetes and that $d b / d b$ mice younger than 5 weeks old are prediabetes. Our present results agree with other reports that the development of diabetes in $d b /$ $d b$ mice was initially characterized by impaired glucose tolerance and hyperinsulinemia associated with decreasing insulin sensitivity $(4,8)$. After 9 weeks old, the age-related decrease in plasma insulin concentration was observed in $d b / d b$ mice, and hyperglycemia continued. Pancreatic insulin content in
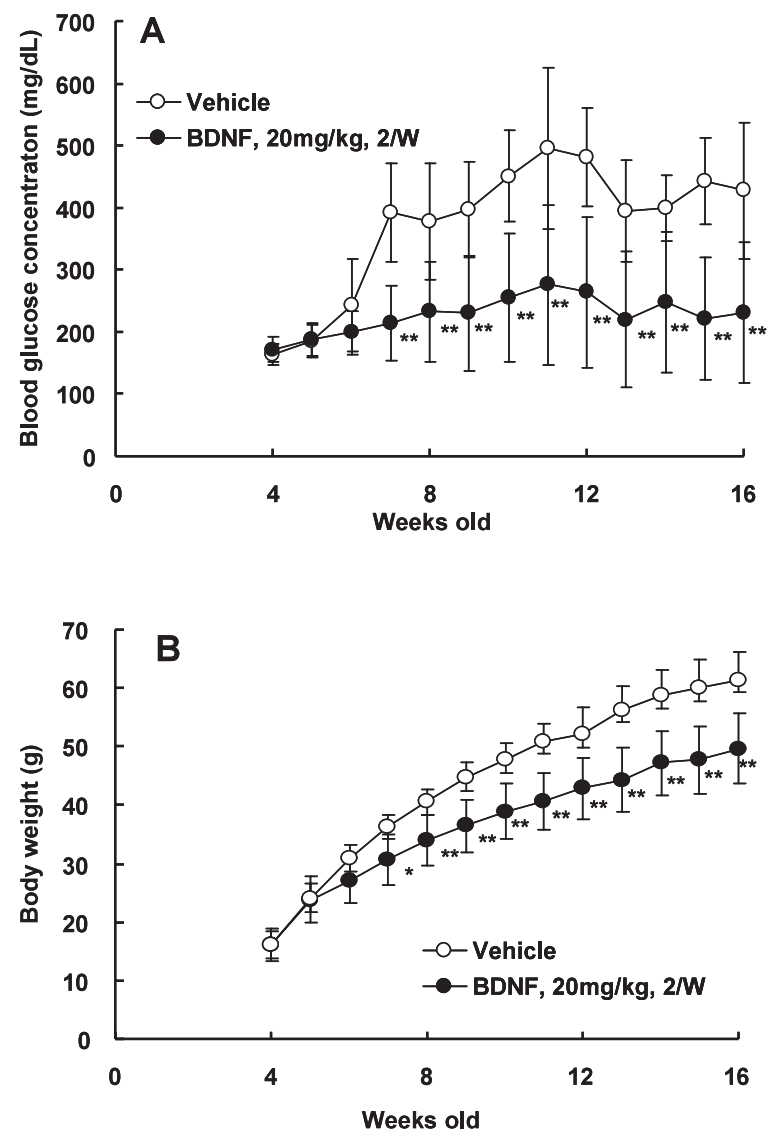

Fig. 4 Effect of intermittent administration of BDNF on prediabetic $d b / d b$ mice. BDNF (20 mg/kg) was administered twice-a-week to 4 week-old $d b / d b$ mice for 12 weeks. Blood glucose concentrations (A) and body weight (B) were indicated. Data are expressed as mean $\pm S D$ (vehicle; $n=7$, BDNF; $\mathrm{n}=11) .{ }^{\star} P<0.05$ and ${ }^{* \star} P<0.01$ vs. vehicle by Student's t-test.

$d b / d b$ mice also decreased after 10 weeks old. Together with reduced insulin sensitivity in peripheral tissues, the impaired insulin secretion from pancreatic $\beta$-cells caused by pancreatic exhaustion is the major abnormality of type 2 diabetes in human diabetic patients $(12,20)$. Thus, it was supposed that $d b / d b$ mice have many similarities in the pathophysiology of diabetes with human diabetic patients.

In the past decade, several randomized controlled trials have been conducted to test the impact of behavioral and pharmacological interventions on development of diabetes in high-risk group (3). These studies have demonstrated that it is possible to reduce the number of people who develop diabetes by $25-62 \%$ over 3- to 6-year time frame (3). Therefore, it is very important to treat early diabetic and prediabetic stages as well as overt diabetes. It has been also reported that thiazolidinediones (TZDs) are in- 


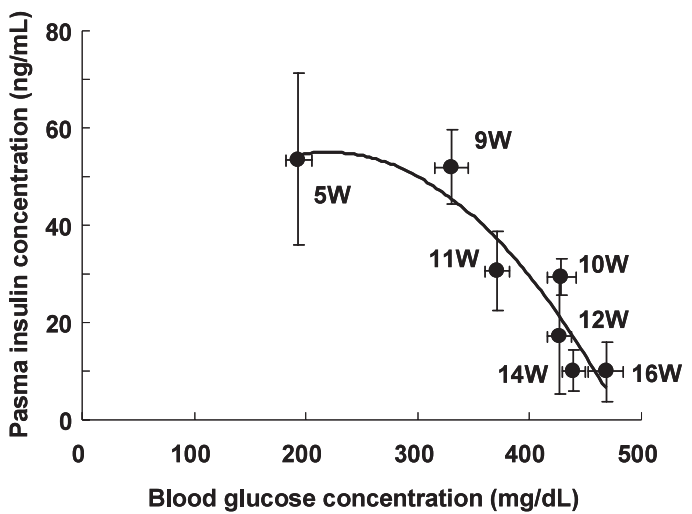

Fig. 5 Relationship between blood glucose concentration and plasma insulin concentration of $d b / d b$ mice. Data are expressed as mean \pm SD $(n=8)$. W; weeks old

sulin-sensitizing agents that slow the progression of diabetes, either delaying or possibly preventing progression to overt diabetes in various diabetic animal models $(2,8)$. Since our previous studies were focused on the effect of BDNF on overt $d b / d b$ mice with severe hyperglycemia, in the present study, we evaluated the effects of BDNF on glycemic control in early diabetic and prediabetic $d b / d b$ mice. In the intervention study using early diabetic $d b / d b$ mice, BDNF prevented the progression of diabetes (Fig. 2A). Interestingly, in the prevention study using prediabetic $d b / d b$ mice, BDNF treatment prevented the age-related increase in blood glucose concentration during the treatment period (Fig. 4A). These results clearly showed for the first time that BDNF prevents the development of diabetes in early diabetic and prediabetic $d b / d b$ mice.

The major pathogenic features of diabetes are insulin resistance and insufficient insulin secretion (20). In the early stages of this disease, insulin secretion from the pancreas increases to compensate for insulin resistance in peripheral tissues $(12,20)$. This excessive demand on the pancreas often results in progressive deterioration of $\beta$-cell function (11). Our previous study has shown that administration of BDNF improves insulin sensitivity in $d b / d b$ mice by enhancing insulin-stimulated PI3-kinase activity in the liver and skeletal muscle (22). In addition, we have demonstrated that BDNF prevented pancreatic exhaustion in $d b / d b$ mice by maintaining the histological cellular organization of $\beta$-cells and non- $\beta$ cells in pancreatic islets, and increasing the number of insulin-containing granules in $\beta$-cells (24). Taken together, although further detailed studies will be needed to unveil the molecular mechanism of BDNF in glycemic control, we suggest that BDNF prevents the development of diabetes by enhancing insulin action in the peripheral tissues and preventing pancreatic exhaustion.

In conclusion, we have demonstrated that intermittent administration of BDNF protected the development of diabetes in $d b / d b$ mice. These data suggest that BDNF may be of therapeutical merit in the treatment of prediabetes and early diabetes such as metabolic syndrome.

\section{REFERENCES}

1. Barbacid M (1995) Neurotrophic factors and their receptors. Curr Opin Cell Biol 7, 148-155.

2. Brand CL, Sturis J, Gotfredsen CF, Fleckner J, Fledelius C, Hansen BF, Andersen B, Ye J, Sauerberg P and Wassermann K (2003) Dual PPAR $\alpha / \gamma$ activation provides enhanced improvement of insulin sensitivity and glycemic control in ZDF rats. Am J Physiol Endocrinol Metab 284, E841-E854.

3. Buchanan TA (2007) (How) can we prevent type 2 diabetes? Diabetes 56, 1502-1507.

4. Chen D and Wang MW (2005) Development and application of rodent models for type 2 diabetes. Diabetes Obes Metab 7, 307-317.

5. Consoli A (1992) Role of liver in pathophysiology of NIDDM. Diabetes Care 15, 430-441.

6. DeFronzo RA (1988) The triumvirate: beta-cell, muscle, liver. A collusion responsible for NIDDM. Diabetes 37, 667687.

7. DeFronzo RA, Bonadonna RC and Ferrannini E (1992) Pathogenesis of NIDDM. A balanced overview. Diabetes Care 15, 318-368.

8. Diani AR, Sawada G, Wyse B, Murray FT and Khan M (2004) Pioglitazone preserves pancreatic islet structure and insulin secretory function in three murine models of type 2 diabetes. Am J Physiol Endocrinol Metab 286, E116-E122.

9. Donahue RP and Orchard TJ (1992) Diabetes mellitus and macrovascular complications: an epidemiological perspective. Diabetes Care 15, 1141-1155.

10. Gerich, JE (1999) Is insulin resistance the principal cause of type 2 diabetes? Diabetes Obes Metab 1, 257-263.

11. Henry RR (1996) Glucose control and insulin resistance in non-insulin-dependent diabetes mellitus. Ann Intern Med 124, 97-103.

12. Kahn CR (1995) Diabetes: causes of insulin resistance. $\mathrm{Na}$ ture 373, 384-385.

13. Lewin GR and Barde YA (1996) Physiology of the neurotrophins. Annu Rev Neurosci 19, 289-317.

14. Lindsay RM, Wiegand SJ, Altar CA and DiStefano PS (1994) Neurotrophic factors: from molecule to man. Trends Neurosci 17, 182-190.

15. Nakagawa $T$, Tsuchida A, Itakura $Y$, Nonomura $T$, Ono $M$, Hirota F, Inoue T, Nakayama C, Taiji M and Noguchi H (2000) Brain-derived neurotrophic factor (BDNF) regulates glucose metabolism by modulating energy balance in diabetic mice. Diabetes 49, 436-444.

16. National Diabetes Data Group (1979) Classification and diagnosis of diabetes mellitus and other categories of glucose intolerance. Diabetes 28, 1039-1057.

17. Ono M, Ichihara J, Nonomura T, Itakura Y, Taiji M, Nakayama C and Noguchi H (1997) Brain-derived neurotrophic factor reduces blood glucose level in obese diabetic mice but 
not in normal mice. Biochem Biophys Res Commun 238, 633-637.

18. Sendtner M, Holtman B and Hughes RA (1996) The response of motoneurons to neurotrophins. Neurochem Res 21, 831-841.

19. Skup MH (1994) BDNF and NT-3 widen the scope of neurotrophin activity: pharmacological implications. Acta Neurobiol Exp 54, 81-94.

20. Stephan M, Michael S, Monika K and Hans-Ulich H (2000) Pathophysiology and pharmacological treatment of insulin resistance. Endocrine Rev 21, 585-618.

21. Tonra JR, Ono M, Liu X, Garcia K, Jackson C, Yancopoulos GD, Wiegand SJ and Wong V (1999) Brain-derived neurotrophic factor improves blood glucose control and alleviates fasting hyperglycemia in C57BLKS-lepr ${ }^{d b} /$ lepr $^{d b}$ mice. Diabetes $48,588-594$.

22. Tsuchida A, Nakagawa T, Itakura Y, Ichihara J, Ogawa W, Kasuga M, Taiji M and Noguchi $H$ (2001) The effects of brain-derived neurotrophic factor on insulin signal transduction in the liver of diabetic mice. Diabetologia 44, 555-566.

23. World Health Organization (1994) Prevention of diabetes mellitus. In: Report of a WHO Study Group (Tech. Rep. Ser., no. 844), World Health Org., Geneva.

24. Yamanaka M, Itakura $Y$, Inoue $T$, Tsuchida A, Nakagawa T, Noguchi H and Taiji M (2006) Protective effect of brainderived neurotrophic factor on pancreatic islets in obese diabetic mice. Metabolism 55, 1286-1292.

25. Yamanaka M, Tsuchida A, Nakagawa T, Noguchi $H$ and Taiji M (2008) Intermittent administration of brain-derived neurotrophic factor (BDNF) ameliorates glucose metabolism and prevents pancreatic exhaustion in diabetic mice. $J$ Biosci Bioeng 105, 395-402.

26. Yuen EC, Howe CL, Li Y, Holtzman DM and Mobley WC (1996) Nerve growth factor and the neurotrophic factor hypothesis. Brain Dev 18, 362-368. 
